DOI: 10.1590/0103-0582201432232101

\title{
Rev Paul Pediatr 2013;31(2):272-5
}

In the article: BRUSCKY, Dayanne Melo V.; ROCHA, Luiz Alexandre R. da; COSTA, Aldo José F.. Recurrence of chronic urticaria caused by reinfection by Helicobacter pylori. Rev. paul. pediatr. São Paulo, v. 31, n. 2, jun. 2013. Available from: $<$ http://www.scielo.br/scielo.php?script=sci_arttext\&pid=S0103-05822013000200021\&lng =pt\&nrm =iso $>$. Cited 2014 Mar 20. http://dx.doi.org/10.1590/S0103-05822013000200021.

Where it said: Dayanne Melo V

Must be read: Dayanne Mota V 